\title{
Development of an Abuse- and Alcohol-Resistant Formulation Based on Hot-Melt Extrusion and Film Coating
}

\author{
Nicole Jedinger, ${ }^{1}$ Simone Schrank, ${ }^{2}$ Johannes M. Fischer, ${ }^{1}$ Karlheinz Breinhälter, ${ }^{1}$ \\ Johannes Khinast, ${ }^{1,3}$ and Eva Roblegg ${ }^{1,2,4}$
}

Received 19 May 2015; accepted 15 July 2015; published online 24 July 2015

\begin{abstract}
This study focused on the development of flexible (i.e., deformable) multiple-unit pellets that feature (i) a prolonged drug release, (ii) drug abuse deterrence, and (iii) a minimal risk of alcohol-induced dose dumping (ADD). Deformable pellets were prepared via an advanced continuous one-step hot-melt extrusion (HME) technique, with the drug (i.e., antipyrine and codeine phosphate) fed as an aqueous solution into the molten matrix material (i.e., cornstarch, gum arabic, and xanthan). Formulations that had suitable mechanical characteristics (i.e., high compression strength) were coated with a flexible Aquacoat ${ }^{\circledR}$ ARC film to ensure prolonged release and to avoid ADD. The pellets were characterized in terms of their mechanical properties and in vitro drug release behavior in alcoholic media. All formulations were abuse deterrent: they had a high compression strength and grinding the pellets into powder was impossible. Since the pellets comprising gum arabic and xanthan as a matrix did not remain intact during dissolution testing, they had a very fast drug release rate. Cornstarch-based pellets that swelled but remained intact in the dissolution media had a slower drug release. Coated cornstarch-based pellets had a prolonged release over $8 \mathrm{~h}$ and resistance to dose dumping in 20 and $40 \%$ ethanol. Our results indicate that cornstarch-based pellets manufactured via the advanced HME process followed by coating are a promising formulation that makes tampering difficult due to a high compression strength combined with robustness in alcoholic media.
\end{abstract}

KEY WORDS: dose dumping; drug tampering; melt extrusion; starch.

\section{INTRODUCTION}

Drug abuse of oral opioids and non-opioid drugs with a narrow therapeutic window, such as benzodiazepines (central nervous system depressants) and amphetamines (stimulants), has received increased public attention in recent years (1). Drug abuse can be defined as "the use of medication for its mind-altering effects, whether or not one also has pain or has been prescribed the medication" (2). Due to their high drug loading and euphoric effects, controlled-release opioid dosage forms that are first-choice formulations for (chronic) pain treatment (3-5) are especially popular among drug abusers (1). Drugs are either chewed or crushed to subsequently snort or dissolve them in common solvents for intravenous injections in order to achieve euphoric and mind-altering effects

\footnotetext{
${ }^{1}$ Research Center Pharmaceutical Engineering, Graz, Austria.

${ }^{2}$ Department of Pharmaceutical Technology, Institute of Pharmaceutical Sciences, University of Graz, Universitätsplatz 1, A- 8010, Graz, Austria.

${ }^{3}$ Institute for Process and Particle Engineering, Graz University of Technology, Graz, Austria.

${ }^{4}$ To whom correspondence should be addressed. (e-mail: eva.roblegg@uni-graz.at)
}

$(1,6,7)$. To counteract these practices, the Food and Drug Administration (FDA) suggested several approaches described in the draft guidance document covering the evaluation and labeling of abuse-deterrent opioids $(7,8)$, which include (i) physical and chemical barriers, (ii) agonist/ antagonist combinations, (iii) aversion, (iv) certain delivery systems, (v) prodrugs, and (vi) combinations thereof (Fig. 1). Physical barriers prevent destruction of the dosage form (e.g., due to increased hardness), whereas chemical barriers impede extraction using common solvents (9). Incorporating an antagonist reduces the euphoria if the drug product is manipulated (e.g., ground). If the drug product is swallowed (i.e., used as prescribed), the antagonist is not clinically active. Aversion is created when upon manipulation, the drug product releases substances that cause unpleasant temporary side effects (e.g., warmth, flushing, itching, sweating). Furthermore, it is recommended to use unattractive delivery systems (e.g., subcutaneous implants). Prodrugs that hinder opioid activity and the associated euphoric effects until they are transformed in the gastrointestinal tract can prevent abuse via the intravenous and nasal routes (9).

Although these are promising tools for ensuring safe and abuse-deterrent drugs, only a few proven products are available on the market and studies in this field are scarce (10-12). 


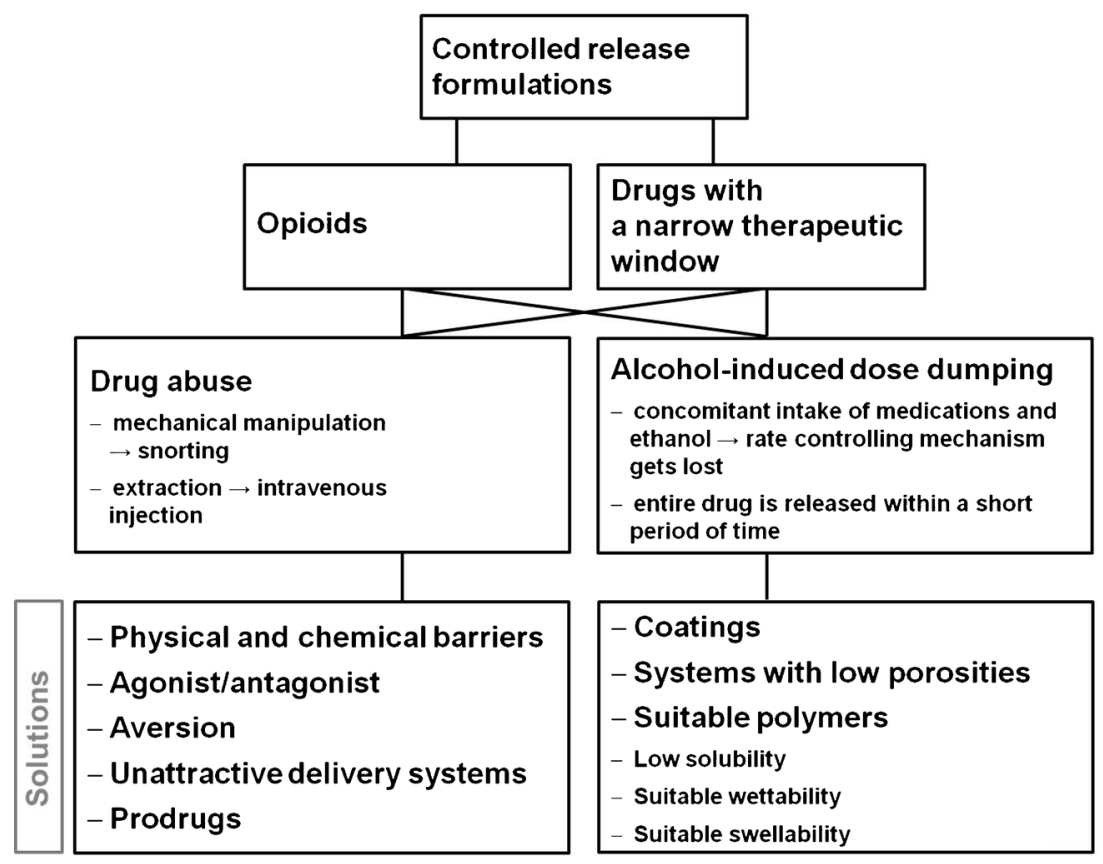

Fig. 1. Systematic overview of drug-abuse- and alcohol-induced dose dumping

Hysingla TM ER tablets (Purdue Pharma) containing hydrocodone bitartrate provide abuse resistance via physical and chemical barriers (13). They are formulated using RESISTEC ${ }^{\mathrm{TM}}$, which obstructs tablet crushing by applying a unique combination of polymer and processing to ensure a high tablet hardness (i.e., physical barrier). Moreover, when dissolved in an aqueous environment, the tablet immediately forms a viscous hydrogel (i.e., chemical barrier) (13), making injecting it impossible. Another abuse-deterrent drug product is Zohydro ${ }^{\circledR}$ ER capsules comprising hydrocodone bitartrate and manufactured via BeadTek $^{\mathrm{TM}}$ (14), a capsule formulation technology that incorporates well-known excipients and is designed to deter abuse. If the capsule is crushed and dissolved in liquids, a viscous gel is immediately formed (14).

Despite existing and hypothetical approaches to make affective abuse-deterrent formulations, tampering with drugs and subsequent drug abuse can never be eliminated entirely. Rather, formulators should focus on reducing the abuse potential by making tampering difficult and time consuming. Such formulations are less attractive to drug abusers, who are reported to spend no more than $10 \mathrm{~min}$ on tampering $(15,16)$.

Another challenge in the development of safe drug products is minimizing the risk of alcohol-induced dose dumping (ADD) (Fig. 1). Concomitant intake of alcoholic beverages and controlled-release oral dosage forms may alter the release-rate-controlling mechanism of the formulation, resulting in an immediate and uncontrolled drug release (17) (e.g., an opioid overdose, which may lead to respiratory depression followed by hypoxia and even death (18)). Especially those patients that suffer from (chronic) pain tend to consume alcohol to cope with the pain-related stress and reduce the pain perception (17).

Overall, there is a growing demand for new flexible technologies for producing safe drug products that prevent both (1) drug abuse and (2) ADD. Recently, Gruenenthal GmbH patented a tamper-resistant oral dosage form comprising a drug with a psychotropic action and an ethylene-vinyl acetate (EVA) polymer (19). Manufactured via thermoforming technologies, such as hot-melt extrusion (HME), it is resistant to solvent extraction, grinding, and dose dumping in aqueous ethanol (19). However, the majority of the existing studies address either abuse deterrence or ADD (20) but not both topics at the same time.

In this study, we focus on the development of multipleunit dosage forms (i.e., pellets) that show a prolonged release and are designed to resist ADD and (due to their high compression strength) tampering with the most common household devices. For pellet preparation, an innovative manufacturing process based on the HME technique was applied. Thereby, the (visco)elastic properties of the matrix materials (i.e., cornstarch, gum arabic, and xanthan) can be achieved by introducing water directly into the matrix melt. Subsequent coating of the pellets ensured a prolonged release of the model drugs (i.e., antipyrine and codeine phosphate) and ADD resistance.

\section{MATERIALS AND METHODS}

\section{Materials}

Antipyrine (Fluka, Sigma Aldrich, St. Louis, USA) and codeine phosphate hemihydrate (donated by G.L. Pharma $\mathrm{GmbH}$, Lannach, Austria) were used as the model drugs. Cornstarch (Carl Roth GmbH, Karlsruhe, Germany), gum arabic (ACM Herba Chemosan AG, Vienna, Austria), and xanthan (Carl Roth $\mathrm{GmbH}$, Karlsruhe, Germany) were the matrix carrier systems. Purified water was used as a plasticizer.

The in vitro drug release studies were carried out with $0.1 \mathrm{~N}$ hydrochloric acid $(\mathrm{HCl})$ and a trisodiumphosphatedodecahydrate buffer purchased from Merck, Darmstadt, Germany. For the dose dumping studies, absolute ethanol (EP) was purchased from VWR International, Darmstadt, Germany. The mobile phase for the reversed-phase (RP) 
high-performance liquid chromatography (HPLC) consisted of MilliQ water, acetonitrile (VWR International, Darmstadt, Germany), phosphoric acid (85\%, VWR International, Darmstadt, Germany), and methanol (LiChrosolv ${ }^{\circledR}$ Reag., EP, VWR International, Darmstadt, Germany). Aquacoat ${ }^{\circledR}$ ARC (Alcohol-Resistant Coating, consisting of ethanolsoluble Aquacoat ${ }^{\circledR}$ ECD 30 and ethanol-insoluble guar gum) from FMC BioPolymer was used for pellet coating. Talc (Carl Roth GmbH, Karlsruhe, Germany) served as an anti-tacking agent, and trieethyl citrate (TEC) (donated by G.L. Pharma $\mathrm{GmbH}$, Lannach, Austria) was applied as a plasticizer for the coating dispersion.

\section{Drug Solubility Determination}

The drug solubility was determined in (a) water, (b) $0.1 \mathrm{~N}$ $\mathrm{HCl}$, (c) $0.1 \mathrm{~N} \mathrm{HCl}$ with ethanol concentrations of 20 and $40 \%$ $(v / v)$, and $(\mathrm{d})$ pure ethanol $(96 \mathrm{v} \%)$. Saturated solutions were prepared and stored in an incubator shaker at $37 \pm 0.5^{\circ} \mathrm{C}$ for $48 \mathrm{~h}$. Samples of $1 \mathrm{ml}$ were taken, filtered through a cellulose acetate filter (pore size $0.2 \mu \mathrm{m}$ ), and, if necessary, diluted. The concentration of the dissolved drug was quantified via $\mathrm{UV} / \mathrm{vis}$ spectrometry at wavelengths of $244 \mathrm{~nm}$ (antipyrine) and $284 \mathrm{~nm}$ (codeine phosphate). The solubility studies were performed in triplicate.

\section{HME Process}

Extrusion was based on the NANEX process (21), which allows side feeding of aqueous drug suspensions and solutions directly into a molten polymer that is miscible with water (22). The matrix material (i.e., cornstarch, xanthan, and gum arabic) in powder form was placed into a co-rotating twin screw extruder (ZSK 18, Coperion GmbH, Stuttgart, Germany). The model drugs (i.e., codeine phosphate hemihydrates and antipyrine) were dissolved in purified water (i.e., plasticizer) at concentrations of 0.5 and $1.0 \mathrm{~g} / \mathrm{ml}$ for codeine phosphate and $1.0 \mathrm{~g} / \mathrm{ml}$ for antipyrine. The solutions were fed from the side into the extruder containing the matrix melt. For codeine phosphate, two concentrations were used to provide different drug loadings while keeping the water content constant. Details regarding the process parameters are summarized in Table I.

The matrix material was fed into the extruder via a gravimetric dosing device (K-Tron, Niederlenz, Switzerland) at a feeding rate of $0.5 \mathrm{~kg} / \mathrm{h}$. The screws had a length-to-diameter ratio (L/D) of 40, and the barrel consisted of 10 individually controllable heating sections. The screw speed was $200 \mathrm{rpm}$. The drug solutions were fed via a calibrated peristaltic pump (Ismatec IP 65, IDEX Health \& Science GmbH, Wertheim, Germany) into barrel 3 of the extruder. The feeding rate of the aqueous solution was adjusted to $100 \mathrm{~g} / \mathrm{h}$ to yield a final drug loading of $20 \%$ for antipyrine and of 10 and $20 \%$ for codeine phosphate. The material was extruded through a die plate with die holes of $1.0 \mathrm{~mm}$ in diameter. The cornstarch/ antipyrine formulation was also extruded through a die plate with die holes of $1.5 \mathrm{~mm}$ diameter. The homogeneous strands were cut directly at the die face using a hot die face pelletizer (23) (Automatik Plastics Machinery GmbH, Großostheim, Germany) with two rotating knives developed in-house. The rotational speed of the knives was adjusted manually to obtain pellets in the desired size range (i.e., $1.25-1.40 \mathrm{~mm}$ ), which were immediately air-cooled (24). An overview of the formulations and the processing parameters is provided in Table I.

Loss on drying (LOD) of the pellets was determined using an oven at $60^{\circ} \mathrm{C}$ for $24 \mathrm{~h}$. Pellets were sieved according to Pharm. Eu. 7.0/2.09.38.00 using analytical DIN sieves (Retzsch $\mathrm{GmbH}$, Haan, Germany). The pellet fractions between 1.25 and $1.4 \mathrm{~mm}$ were applied for further characterization studies.

\section{Coating Process}

Selected pellet formulations were coated with Aquacoat ${ }^{\circledR}$ ARC, as proposed by Rosiaux et al. (25-27). The coating dispersion was prepared by mixing Aquacoat ${ }^{\circledR}$ ECD 30 and guar gum at a ratio of 93:7. Prior to mixing, Aquacoat ${ }^{\circledR}$ ECD 30 was plasticized with $25 \%$ TEC ( $w / w$; based on the total polymer content) at room temperature for $30 \mathrm{~min}$. Guar gum was dissolved in purified water under stirring at $65^{\circ} \mathrm{C}$ for $2 \mathrm{~h}$. After cooling down to room temperature, the two solutions were mixed and stirred for $30 \mathrm{~min}$. To reduce the stickiness of the coating formulation, talc $(50 \% \mathrm{w} / \mathrm{w}$; based on the total polymer content) was added as an anti-tacking agent.

The pellets were coated in a fluidized bed coater (Mycrolab H00472, Oystar Hüttlin, Schopfheim, Germany) equipped with a bottom sprayer. The coating conditions were as follows: inlet air volume $25 \mathrm{~m}^{3} / \mathrm{h}$, inlet air temperature $38^{\circ} \mathrm{C}$, spray rate $2 \mathrm{~g} / \mathrm{min}$, spray air pressure $1.2 \mathrm{bar}$, microclimate pressure 0.6 bar, nozzle diameter $1.2 \mathrm{~mm}$, and coating level $20 \%$. After coating, the pellets were dried in the fluidized bed coater for $15 \mathrm{~min}$.

\section{Characterization of Drug-Loaded Pellets}

\section{Differential Scanning Calorimetry Analysis}

The solid-state properties of the hot-melt-extruded pellets were characterized using a differential scanning calorimeter (DSC 204F1 Phoenix ${ }^{\circledR}$, Netzsch GmbH, Selb, Germany). For comparison reasons, we evaluated the thermal behavior of the model drugs, the matrix materials, and mixtures of the matrix materials with $20 \%$ purified water that acted as a plasticizer during extrusion. Samples of about $5 \mathrm{mg}$ were placed into hermetically sealed aluminum crucibles and scanned with pure nitrogen as the analytical gas between 25 and $200^{\circ} \mathrm{C}$ at a heating rate of $50 \mathrm{~K} / \mathrm{min}$ and at a flow rate of $20 \mathrm{ml} / \mathrm{min}$. After cooling to $25^{\circ} \mathrm{C}$ at $10 \mathrm{~K} / \mathrm{min}$, a second heating run was performed. An empty aluminum crucible was used as a reference. The DSC data analysis was conducted with Proteus Thermal Analysis software (Netzsch GmbH, Selb, Germany). Each sample was evaluated in triplicate.

\section{Pellet Compression Strength}

The pellet compression strength was determined with a conventional tablet hardness tester (PTB 111 E, Pharma Test, Hainburg, Germany) by recording the hardness values of 10 randomly picked pellets from each batch.

Additionally, the compression force of the pellets was studied using a rheometer (Physica MCR 301, Anton Paar GmbH, Graz, Austria) equipped with a parallel plate measuring system in the non-rotational mode. A single pellet was manually placed in the center of the lower plate. The upper plate was moved 
Table I. Formulations and Process Parameters Applied During HME

\begin{tabular}{|c|c|c|c|c|c|c|c|c|c|c|c|c|c|c|}
\hline \multirow[t]{3}{*}{ Formulation } & \multirow{3}{*}{$\begin{array}{l}\text { Matrix } \\
\text { material }\end{array}$} & \multirow{3}{*}{$\begin{array}{l}\text { Active ingredient } \\
\quad(w t \%)\end{array}$} & \multicolumn{11}{|c|}{ Process parameters } & \multirow{3}{*}{$\begin{array}{l}\text { Knife } \\
\quad \text { rotational } \\
\quad \text { speed }(\mathrm{rpm})\end{array}$} \\
\hline & & & \multirow{2}{*}{$\begin{array}{c}\text { Torque } \\
(\%)\end{array}$} & \multicolumn{10}{|c|}{ Barrel zone temperatures $\left({ }^{\circ} \mathrm{C}\right)$} & \\
\hline & & & & 1 & 2 & 3 & 4 & 5 & 6 & 7 & 8 & 9 & 10 & \\
\hline 1 & Cornstarch & Without $\left(20 \% \mathrm{H}_{2} \mathrm{O}\right)$ & 18 & 65 & 85 & 85 & 85 & 85 & 85 & 85 & 85 & 85 & 85 & 1300 \\
\hline 2 & Cornstarch & $\begin{array}{l}\text { Antipyrine } 20 \% \\
\quad \text { (aqueous solution) }\end{array}$ & 7 & 65 & 85 & 85 & 85 & 85 & 85 & 85 & 85 & 85 & 85 & 1500 \\
\hline 3 & Cornstarch & $\begin{array}{l}\text { Codeine phosphate } 10 \% \\
\text { (aqueous solution) }\end{array}$ & 22 & 65 & 85 & 85 & 85 & 85 & 85 & 88 & 88 & 88 & 87 & 1500 \\
\hline $4^{\mathrm{a}}$ & Cornstarch & $\begin{array}{l}\text { Codeine phosphate } 20 \% \\
\quad \text { (aqueous solution) }\end{array}$ & - & - & - & - & - & - & - & - & - & - & - & - \\
\hline 5 & Xanthan & Without $\left(20 \% \mathrm{H}_{2} \mathrm{O}\right)$ & 16 & 70 & 85 & 85 & 85 & 85 & 85 & 85 & 85 & 85 & 85 & 1600 \\
\hline 6 & Xanthan & $\begin{array}{l}\text { Antipyrine } 20 \% \\
\quad \text { (aqueous solution) }\end{array}$ & 2 & 50 & 50 & 63 & 85 & 85 & 85 & 85 & 85 & 85 & 83 & 2000 \\
\hline 7 & Gum arabic & Without $\left(20 \% \mathrm{H}_{2} \mathrm{O}\right)$ & 25 & 60 & 65 & 75 & 75 & 75 & 75 & 75 & 75 & 74 & 74 & 1600 \\
\hline 8 & Gum arabic & $\begin{array}{l}\text { Antipyrine } 20 \% \\
\quad \text { (aqueous solution) }\end{array}$ & 11 & 60 & 60 & 65 & 65 & 65 & 65 & 65 & 65 & 60 & 65 & 1600 \\
\hline
\end{tabular}

${ }^{a}$ Adding $20 \%$ codeine phosphate resulted in highly viscous strands that were not suitable for hot die face pelletizing

down at a constant velocity of $0.5 \mu \mathrm{m} / \mathrm{s}$. Based on the force displacement diagrams, the maximum force of plastic deformation upon pellet fraction $(F)$ was determined. The crushing strength $(\sigma)$ was calculated from $F$ and the diameter of each pellet $(d)$ according to Shipway et al. (28):

$\sigma=\frac{1.6 F}{\pi d^{2}}$

From each batch, 50 pellets were tested with the rheometer.

\section{In Vitro Dissolution Studies}

All in vitro dissolution tests were carried out via the USP 28 rotating basket method $<711>$ in a USP apparatus I (Pharma Test, Hainburg, Germany). The rotational speed was $100 \mathrm{rpm}$, and the temperature was $37 \pm 0.5^{\circ} \mathrm{C}$. The dissolution medium consisted of $750 \mathrm{ml} 0.1 \mathrm{~N} \mathrm{HCl}$. After $2 \mathrm{~h}$, $250 \mathrm{ml}$ trisodiumphosphate-dodecahydrate buffer was added to increase the $\mathrm{pH}$ from 1.2 to 6.8. For the ADD studies, we used $900 \mathrm{ml} \mathrm{HCl}(0.1 \mathrm{~N})$ with ethanol concentrations of $20 \%$ (equivalent to mixed drinks) and $40 \%$ (equivalent to hard liquor) $(v / v)$ and tested them for $2 \mathrm{~h}$. The pellet sample weight was adjusted to $1 \mathrm{~g}$ to ensure perfect sink conditions in all dissolution media without exceeding the maximum single dose. Samples of $1 \mathrm{ml}$ were withdrawn at predetermined time intervals. Each batch was investigated in triplicate.

To compare the drug release profiles in alcoholic and non-alcoholic media, the $f_{2}$ similarity factor was used (29):

$f_{2}=50 \times \log \left\{\left[1+\frac{1}{n} \sum_{t=1}^{n}\left(R_{t}-T_{t}\right)^{2}\right]^{-\frac{1}{2}} \times 100\right\}$

where $n$ is the number of dissolution time points considered and $R_{t}$ and $T_{t}$ are the percentages of drug dissolved of the reference and test formulations at time point $t$. In general, an $f_{2}$ value in the range of 50-100 indicates that the dissolution profiles are similar.

\section{Drug Quantification}

Drug quantification of the dissolution samples was performed via reversed-phase (RP) high-performance liquid chromatography (HPLC) for antipyrine and via UV/vis spectroscopy for codeine phosphate.

The HPLC analysis was carried out using a MerckHitachi system (Tokyo, Japan) at $35^{\circ} \mathrm{C}$. As the stationary phase, a C18 MOS-Hypersil column $(250 \times 4 \mathrm{~mm} \times 5 \mu \mathrm{m} ; 120 \AA$ pore size; VDS optilab, Berlin, Germany) was applied. The mobile phase consisted of MilliQ water, which was adjusted to $\mathrm{pH} 3.0$ with phosphoric acid and a 50:50 $(\mathrm{v} / \mathrm{v})$ mixture of acetonitrile and methanol (isocratic mode 58:42 (v/v)). The injection volume was $20 \mu \mathrm{l}$ and the flow rate was $1 \mathrm{ml} / \mathrm{min}$. The drug was analyzed with a model series L-4250 UV-VIS detector at a wavelength $230 \mathrm{~nm}$. For quantification, a single-point calibration with $100 \%$ standard solution of the active pharmaceutical ingredient (API) was used.

The codeine phosphate quantification was performed with a UV spectrophotometer (Spectronic Genesys 5, Spectronic Instruments Inc., Rochester, USA) at a wavelength of $248 \mathrm{~nm}$. The samples were diluted, if necessary, and quantified via an external standard (i.e., calibration curve).

\section{RESULTS AND DISCUSSION}

\section{Drug Solubility Determination}

Since a drug's solubility in the dissolution medium strongly affects the dissolution rate, the solubility of antipyrine and codeine phosphate was determined in water, acidic media with and without ethanol (20 and 40\%), and in 96\% ethanol (Fig. 2). The results indicate that antipyrine is highly soluble in all tested media. The ethanol content did not affect the solubility until its concentration reached 40\%. In 96\% ethanol, the solubility decreased significantly due to the different polarity/dielectric constants of the solute and the solvent. However, antipyrine was still highly soluble in $96 \%$ ethanol (30). In contrast, the solubility of codeine phosphate markedly 


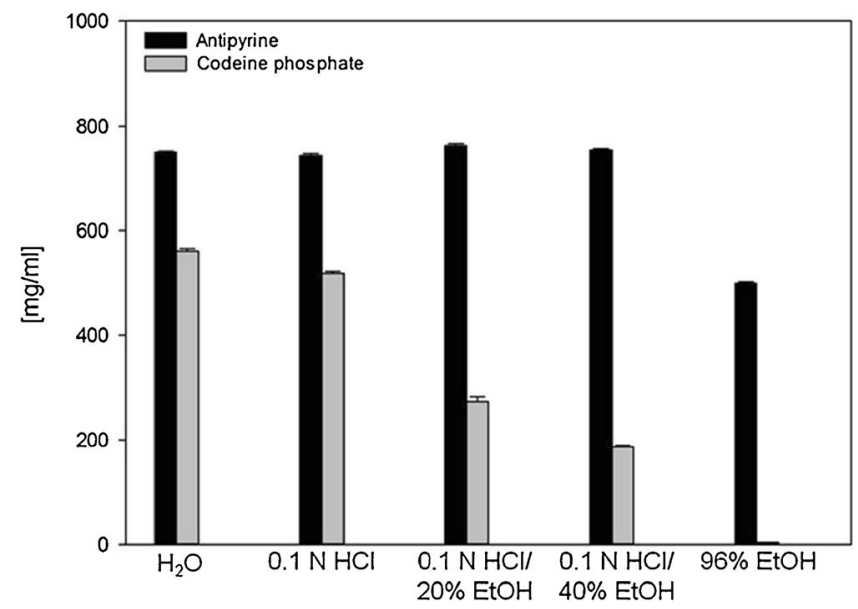

Fig. 2. Solubility of model drugs in various media at $37 \pm 0.5^{\circ} \mathrm{C}$. Mean values $\pm \mathrm{SD}(n=3)$. As the standard deviation was very low, it is not clearly visible from the graph. Solubility of codeine phosphate is based on the data of Jedinger et al. (27)

decreased with the increasing ethanol concentrations (31) and was very low in $96 \%$ ethanol. It can be concluded that the addition of ethanol lowered the dielectric constant in relation to pure water, and hence, the solubility decreased $(17,32,33)$.

\section{Preparation of Pellets via HME}

According to the literature, extrusion of pure native starch is not possible and adding water is required to achieve gelatinization and to transform starch into a homogeneous matrix (34). Starch is composed of $\alpha$-D-glucosyl units. It comprises amorphous regions as well as crystalline domains in the short-chain clusters of amylopectin. During extrusion, the starch granules are destroyed by mechanical disruption of molecular bonds due to the intense shear forces within the extruder and loss of crystallinity is caused (i.e., gelatinization of starch) (35).

When cornstarch was extruded in our experiments with water at process temperatures between 65 and $85^{\circ} \mathrm{C}$, glassy-like yellowish spherical pellets with a smooth, homogeneous surface structure were obtained. The pellets were very flexible and elastic, exhibiting mechanical properties suitable for abuse-deterrent dosage forms.

To the best of our knowledge, xanthan and gum arabic have not been used as matrix materials for HME to date. Xanthan is assigned to the polysaccharides from the chemical point of view and comprises D-glucose, D-mannose, and D-glucuronic acid. Gum arabic is a complex mixture of glycoproteins and polysaccharides. Both, xanthan and gum arabic are crystalline. During extrusion, it is assumed that crystallite softening occurs.

When gum arabic and xanthan were extruded without any plasticizers (i.e., water) at process temperatures of 60 $85^{\circ} \mathrm{C}$, a non-molten powdery and brittle mass was obtained. At higher process temperatures (i.e., $80-200^{\circ} \mathrm{C}$ ), the substances failed to melt and became charred. However, when water was added as a plasticizer, smooth pellets with a yellowish coloration were produced via HME. They were slightly sticky since the amount of water added was rather high ( $\sim 20 \%)$, which was necessary to obtain suitable strands for further downstream processing (die face cutting). The gum arabic and xanthan pellets had a cylindrical shape, possibly due to faster solidification (and thus less time for forming a spherical shape), compared to cornstarch (24). Nevertheless, they were considered to be suitable for providing abuse deterrence due to their deformable character.

The next step was to incorporate drugs at various concentrations. While adding antipyrine to the starch matrix decreased the torque from 18 to $7 \%$ (Table I) due to the plasticizing effect of the drug, incorporating codeine phosphate increased the torque values (i.e., 22\%; Table I). Adding 20\% codeine phosphate resulted in highly viscous strands that were not suitable for hot die face pelletizing. Decreasing the drug loading to $10 \%$ yielded strands that could be cut into spherical pellets via die face pelletizing. Once again, the pellets were very flexible and elastic.

Incorporating antipyrine into the xanthan matrix decreased the extrusion temperatures from $70-85$ to $50-83^{\circ} \mathrm{C}$ due to the plasticizing effect of the drug. This is confirmed by the torque value that decreased from 16 to $2 \%$ (Table I). Adding antipyrine to the gum arabic matrix slightly reduced the required process temperatures (i.e., from 60-75 to 60$65^{\circ} \mathrm{C}$ ). Additionally, the torque decreased from 25 to $11 \%$ (Table I), indicating the plasticizing effect of antipyrine. Similarly to the drug-free pellets, the drug-loaded xanthan and gum arabic pellets were smooth and sticky, with a yellowish coloration. As before, the pellets were not spherical but rather cylindrical in shape. The placebo pellets exhibited approximately $20 \% w / w$ LOD, which decreased by drug addition. Incorporating antipyrine led to approximately $17 \% \mathrm{w} / \mathrm{w}$ LOD for all pellet formulations. The cornstarch/codeine phosphate pellets showed $15 \% \mathrm{w} / \mathrm{w}$ LOD. However, the added total amount of water was kept constant for all formulations. It is assumed that the lower weight loss during drying of antipyrine- and codeine-phosphate-containing pellets may be due to drug-bound water.

The pellets that were extruded with the $1.0-\mathrm{mm}$ die had a yield of $>50 \%$ of the sieve fraction between 1.25 and $1.40 \mathrm{~mm}$.

\section{Characterization of Pellets}

\section{Thermal Characterization}

First, we evaluated the thermal behavior of the matrix materials in the presence of water (i.e., a plasticizer during 
extrusion) via DSC (Fig. 3a-d). For pure cornstarch and xanthan, a broad endothermic event with an onset at 107.4 and $115.0^{\circ} \mathrm{C}$ was recorded during the first heating cycle (data not shown) due to water loss (36). Upon cooling and reheating, no thermal events were observed. The glass transition (Tg) of pure cornstarch, which occurs at around $58^{\circ} \mathrm{C}$ (37), was not detected via conventional DSC with comparatively low heating rates $(37,38)$. The thermogram of pure gum arabic showed no thermal events in the investigated temperature range (i.e., $20-200^{\circ} \mathrm{C}$ ). Adding water to the
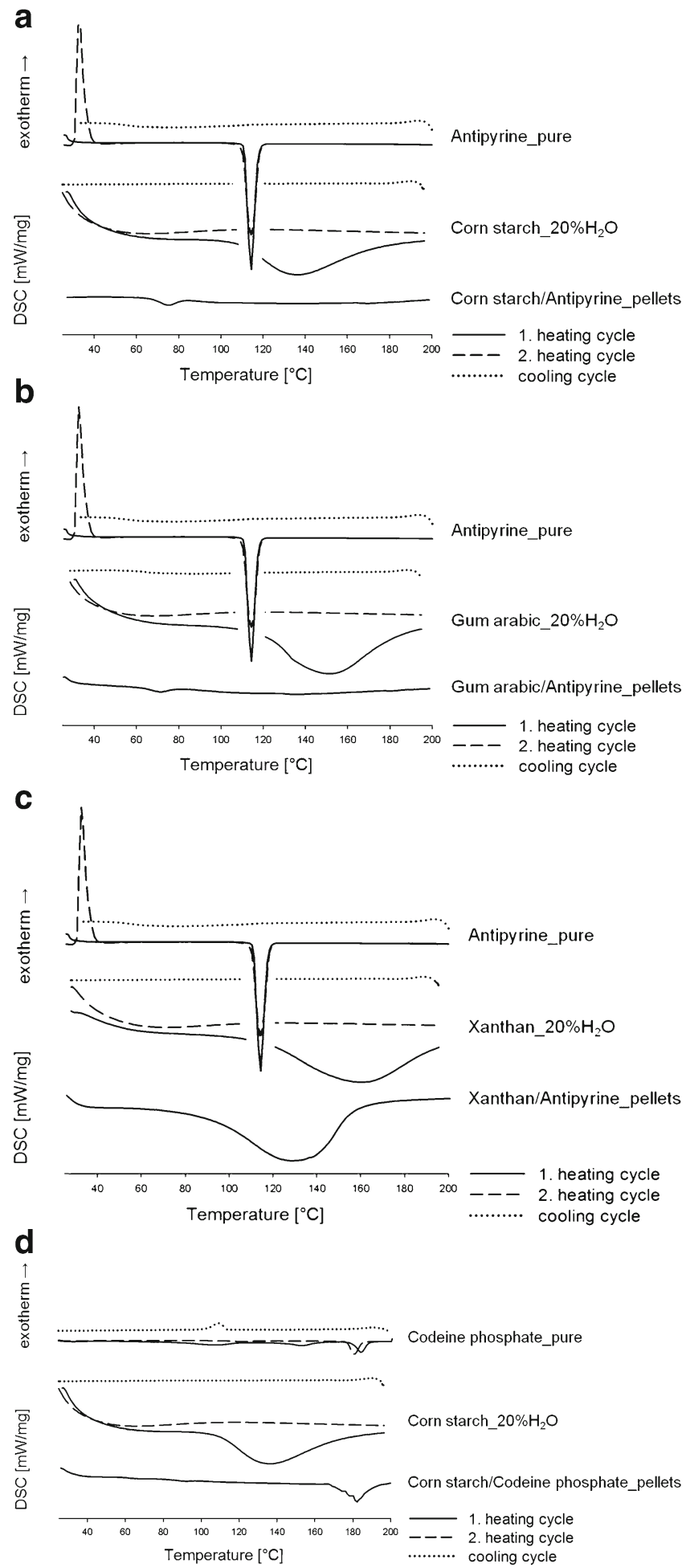

Fig. 3. a-d DSC scans of the model drugs (i.e., antipyrine, codeine phosphate), matrix materials (i.e., cornstarch, gum arabic, xanthan) with the addition of $20 \%$ purified water (two heating cycles shown), and hot-melt-extruded pellets (one heating cycle shown) 

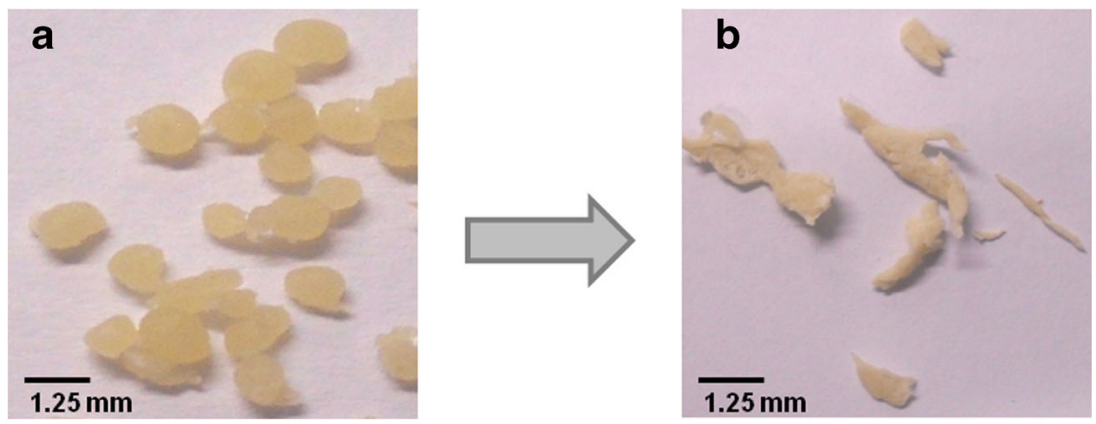

Fig. 4. Hot-melt-extruded xanthan/antipyrine (20\%) pellets a before and $\mathbf{b}$ after grinding with a mortar and a pestle

matrix materials resulted in a broad endotherm with an onset between 100 and $120^{\circ} \mathrm{C}$ due to water evaporation (Fig. 3a-d). No thermal events were observed during cooling and the second heating cycle for all matrix materials. Since no degradation occurred under $200^{\circ} \mathrm{C}$, the matrix materials were considered to be stable at the applied extrusion temperatures (i.e., $\left.50-85^{\circ} \mathrm{C}\right)$.

Additionally, DSC was used to investigate the solid state of the model drugs and hot-melt-extruded pellets (Fig. 3a-d). The thermogram of the first heating cycle of antipyrine clearly indicated one sharp endotherm at $113.6^{\circ} \mathrm{C}$ (onset $107.6^{\circ} \mathrm{C}$ ), which corresponds to melting. No thermal events were observed during cooling, suggesting that the drug was in its amorphous state after cooling. Upon reheating, one exothermic event and one endothermic event were recorded. The exothermic signal at $31.8^{\circ} \mathrm{C}$ (onset $26.5^{\circ} \mathrm{C}$ ) was due to recrystallization of the amorphous drug, followed by melting at $113.6^{\circ} \mathrm{C}$ (onset $104.7^{\circ} \mathrm{C}$ ) (39). Upon heating, codeine phosphate had three endothermic events (Fig. 3d) corresponding to water loss, structural rearrangement, and melting. For detailed interpretation, please refer to Jedinger et al. (31).

The DSC scan of the cornstarch/antipyrine pellets indicated one endothermic event at $70.8^{\circ} \mathrm{C}$ (onset $63.3^{\circ} \mathrm{C}$ ) (Fig. 3a). The endotherm was attributed to the gelatinization (melting) of the starch granules, which occurs at around $70^{\circ} \mathrm{C}$ with high water contents (40). For the gum arabic/antipyrine pellets, one endotherm was detected at $71.0^{\circ} \mathrm{C}$ (onset $63.7^{\circ} \mathrm{C}$ ), which corresponds to crystallite melting of gum arabic (Fig. 3b) (41). During the first heating of xanthan/antipyrine pellets, a broad endothermic event occurred at $129.4^{\circ} \mathrm{C}$ (onset
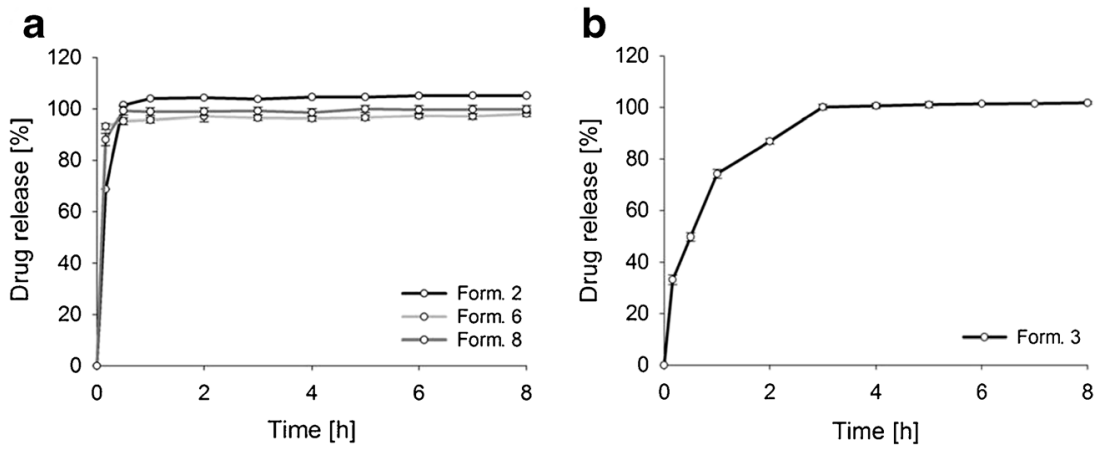

Fig. 5. In vitro drug release profiles of the following: a formulation 2 (cornstarch/antipyrine (20\%) pellets), formulation 6 (xanthan/antipyrine (20\%) pellets), and formulation 8 (gum arabic/antipyrine (20\%) pellets), and $\mathbf{b}$ formulation 3 (cornstarch/codeine phosphate $(10 \%)$ pellets) in non-alcoholic media over $8 \mathrm{~h}$. Mean values \pm SD $(n=3)$. As SDs were very low, they are not clearly visible in the graph $88.7^{\circ} \mathrm{C}$ ) due to moisture evaporation (Fig. $3 \mathrm{c}$ ). Since the melting peak of antipyrine did not show in the heating thermograms of starch/antipyrine and gum arabic/antipyrine pellets, it was assumed that the drug molecularly dissolved in the matrix, which agrees with previous studies $(24,42)$. For the xanthan/antipyrine pellets, the solid state of antipyrine could not be determined since the melting endotherm of antipyrine appears in the same temperature range as the moisture evaporation does.

The thermogram of the cornstarch/codeine phosphate pellets suggests an endothermic event at $181.2^{\circ} \mathrm{C}$ (onset $176.4^{\circ} \mathrm{C}$ ), which corresponds to the structural rearrangement (43) of codeine phosphate (Fig. 3d). The presence of crystalline codeine phosphate indicates that the drug did not molecularly dissolve in the cornstarch matrix. However, the characteristic endotherm of the drug broadened and shifted slightly towards lower temperature.

No thermal events were observed during cooling and the second heating cycle for all pellet formulations (data not shown).

\section{Pellet Compression Strength and Physical Manipulation}

The compression force of the drug-loaded pellet formulations exceeded the maximum force that can be applied by the rheometer (i.e., $50 \mathrm{~N}$ ). All tested pellets deformed but yet did not break, suggesting that the force required for compression was higher than $50 \mathrm{~N}$. Consequently, the compression force could not be determined and the compression strength could not be calculated from Eq. (1). 


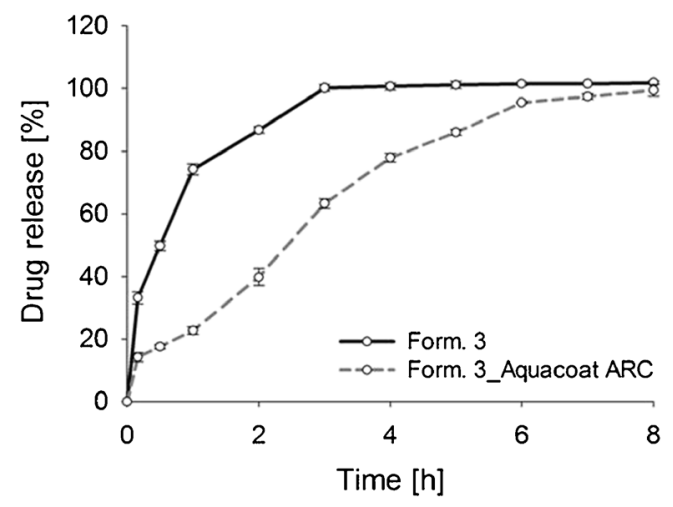

Fig. 6. In vitro drug release profiles of formulation 3 (cornstarch/ codeine phosphate $(10 \%)$ pellets) and formulation 3 coated with $20 \%$ Aquacoat $^{\circledR}$ ARC in non-alcoholic media over $8 \mathrm{~h}$. Mean values $\pm \mathrm{SD}(n=3)$

Additionally, the compression force was determined via a conventional tablet hardness tester with a maximum applicable force of $500 \mathrm{~N}$. Again, the pellets deformed but did not recover (i.e., plastic deformation), implying that the force necessary to crush the pellets exceeds even $500 \mathrm{~N}$. That means that a single pellet can be loaded with a mass of $50 \mathrm{~kg}$ without being crushed.

Physical (mechanical) manipulation was tested according to the FDA's draft guidance on abuse-deterrent opioids (8): the pellet formulations were ground first with a spoon (i.e., a common household device) and then, more sophisticated, with a mortar and a pestle. Both manipulation methods resulted in large sticky fragments and no fine powders were obtained (Fig. 4). This shows that physical manipulation is impeded for all tested pellet formulations due to their high compression strengths independent upon the formulation composition.

\section{In Vitro Drug Release of Hot-Melt-Extruded Pellets}

Figure 5a illustrates the API release from the antipyrine pellets in non-alcoholic media. Due to the physicochemical properties of both, the pellet matrix and the drug, all pellets had an immediate drug release. High solubility of antipyrine in the dissolution media (i.e., $743.3 \mathrm{mg} / \mathrm{ml}$ ) led to a fast drug release. Dissolution was fast also because the tested matrix materials (gum arabic, xanthan, and cornstarch) did not contain their shape during dissolution testing and did not retard release. Hence, diffusion of dissolved antipyrine through the

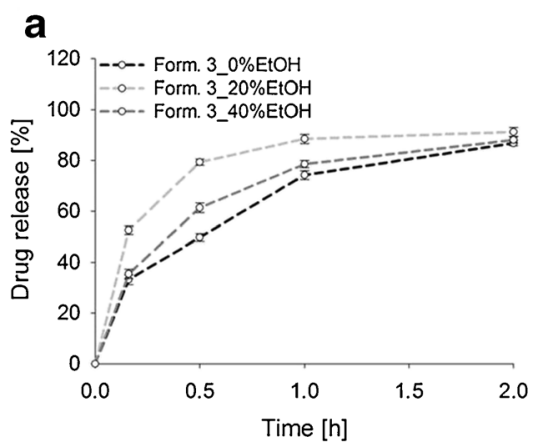

matrix was not a rate-limiting step. While the gum-arabicbased pellets dissolved completely within 30 min due to physical erosion and subsequent degradation (44), the xanthan pellets swelled without dissolving, forming a highly viscous gel due to uncoiling of the structure and the formation of hydrogen bonds with the water molecules (45). Typically, a gel layer forming on the outer surface of a dosage form is considered to control drug release (46). However, the pellets produced in the process had a high specific surface area, resulting in complete hydration and dissolution of the pellets. After $30 \mathrm{~min}$, individual pellets were not visible anymore and the rate-controlling effect was not observed. Also, the cornstarch pellets swelled to a great extent. Here, individual pellets were still present throughout dissolution testing (see also Bialleck et al. (24)). Again, the hydrophilic gel layer that formed upon contact with the aqueous media did not control the drug release due to the high specific surface area of the pellets.

Since starch was the most promising matrix for achieving a prolonged drug release, a different model drug, codeine phosphate, was incorporated. As illustrated in Fig. 5b, the amount of codeine phosphate released was lower compared to the starch/antipyrine pellets. Around $33 \%$ of codeine phosphate was detected in the dissolution media after $10 \mathrm{~min}$. The pellets continued the drug release for $2 \mathrm{~h}$, followed by an entire release of the API after $3 \mathrm{~h}$. This can be explained by a lower solubility of codeine phosphate in $0.1 \mathrm{~N} \mathrm{HCl}$ compared to antipyrine.

Although none of the cornstarch-based formulations had a prolonged release profile, they stayed intact throughout the dissolution testing. Together with their elastic behavior and high mechanical resistance to tampering with common household devices, this makes cornstarch-based codeine-phosphateloaded pellets perfect candidates for further development. Thus, Aquacoat ${ }^{\circledR}$ ARC, a coating material known to retard drug release and to prevent ADD, was applied $(25,27,47)$. Aquacoat ${ }^{\circledR}$ ARC consists of ethanol-soluble Aquacoat ${ }^{\circledR}$ ECD 30 and ethanol-insoluble guar gum. Aquacoat ${ }^{\circledR}$ ECD 30 remains intact in water and thus retards the release in aqueous media. The rate-controlling effect of the coating in the presence of ethanol is due to guar gum, which is insoluble in ethanol (47). Thereby, guar gum acts as a protective layer for the ethanol-soluble ethylcellulose, leaving the releasecontrolling film intact in the presence of ethanol (47). Moreover, guar gum increases the mechanical strength of the film (27), which is further enhanced by adding TEC (plasticizer),

\section{b}

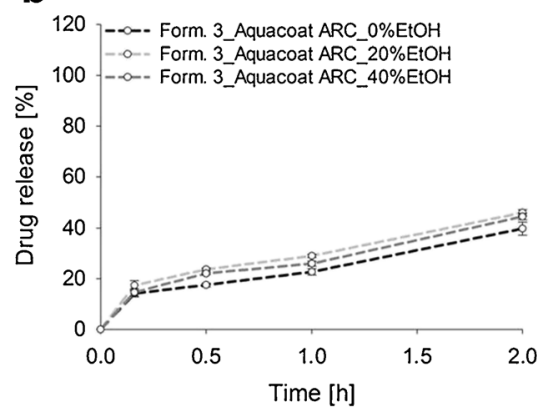

Fig. 7. In vitro drug release profiles of a formulation 3 (cornstarch/codeine phosphate $(10 \%)$ pellets) and $\mathbf{b}$ formulation 3 coated with $20 \%$ Aquacoat $^{\circledR}$ ARC in alcoholic media over $2 \mathrm{~h}$. Mean values \pm SD $(n=3)$ 

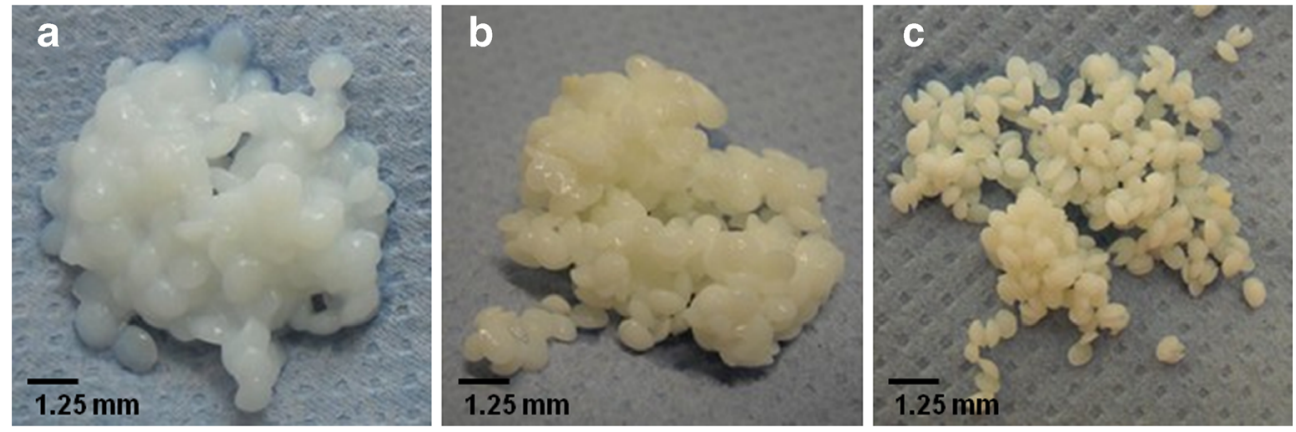

Fig. 8. Swelling behavior of cornstarch/codeine phosphate pellets after $2 \mathrm{~h}$ of exposure to a $0.1 \mathrm{~N} \mathrm{HCl}, \mathbf{b}$ $0.1 \mathrm{~N} \mathrm{HCl} / 20 \% \mathrm{EtOH}$, and $\mathbf{c} 0.1 \mathrm{~N} \mathrm{HCl} / 40 \% \mathrm{EtOH}$

resulting in high elongation at breaking. The cornstarch pellets also showed high compression strengths and did not break but rather deformed, which means that grinding was impossible. Thus, if two highly flexible systems are combined, the possibility for abuse by mechanical destruction is decreased.

The dissolution studies of the coated pellets demonstrated that a coating level of $20 \%$ led to a significantly $(p<0.05)$ decreased drug release rate, compared to the non-coated pellets (Fig. 6). After $1 \mathrm{~h}, 20 \%$ of the drug was released, and after $2 \mathrm{~h}$, only $40 \%$ was detected in the dissolution media. This indicates that adding Aquacoat ${ }^{\circledR}$ ARC was suitable for achieving a prolonged release from cornstarch pellets. To verify if this coating material can be alcohol resistant for $2 \mathrm{~h}$, the pellets were tested in 20 and $40 \%$ ethanolic media and compared with the uncoated pellet formulation.

Figure 7 a clearly shows that the drug release of uncoated pellets depends on the ethanol concentration. Interestingly, the pellets were robust in $40 \%$ alcoholic media $\left(f_{2}=59.77\right)$. However, adding $20 \%$ ethanol to acidic media markedly increased the drug release rate $\left(f_{2}=35.86\right)$ and led to dose dumping. This can be attributed to the effect of ethanol on the starch gel layer formation and the solubility of codeine phosphate $(17,48)$. In general, the swelling behavior and the API release depend on the penetration of dissolution media into the pellet. Thereby, the free volume between the polymer chains increases and a gel layer that controls the drug release is formed (48). Upon contact with acidic media (without any ethanol) the cornstarch/codeine phosphate pellets immediately begin to swell. The formed gel layer acts as a protective barrier, which controls diffusion of the drug from the pellets and the drug release rate. Adding ethanol to the dissolution media inhibits the initial interaction between the ethanolinsoluble cornstarch matrix and the surrounding media and hinders the formation of a uniform and stable gel layer, leading to an uncontrolled release of the drug from the pellets. As such, the drug release rate is not controlled by the gel layer but is rather a function of the drug's solubility in ethanol, which is lower in $40 \%$ ethanol than in $20 \%$ ethanol (i.e., 186.09 and $273.33 \mathrm{mg} / \mathrm{ml}$, respectively). Figure 8b, c clearly indicates that swelling is impeded with increasing alcohol content.

Figure $7 \mathrm{~b}$ shows that drug release from the coated cornstarch/codeine phosphate pellets was not significantly affected by adding 20 and $40 \%$ ethanol ( $p=0.54$ and 0.72 ). The estimated $f_{2}$ values of 62.13 and 70.96 confirmed that no dose dumping occurred. Again, the drug release was higher in $20 \%$ than in $40 \%$ alcoholic media, which was also observed in a previous study (31).

\section{CONCLUSIONS}

This paper reports the development of drug-abusealcohol-deterrent multi-unit dosage forms (i.e., pellets) based on matrix systems (i.e., cornstarch, gum arabic, xanthan). The pellets were manufactured via an advanced, continuous onestep HME process, during which a defined amount of water was directly fed into the matrix melt yielding deformable pellets that are tamper resistant. Formulations based on xanthan and gum arabic showed immediate drug release (i.e., complete release within less than $30 \mathrm{~min}$ ). In contrast, cornstarch-based pellets retarded the drug release up to $3 \mathrm{~h}$. To prolong the drug release and to provide resistance against ADD, cornstarch pellets were coated with Aquacoat ${ }^{\circledR}$ ARC. Overall, it was shown that processing cornstarch via advanced HME increased its resistance to common tampering practices. In combination with a coating process, this matrix system has the potential not only to diminish the abuse but also to prevent $\mathrm{ADD}$.

\section{ACKNOWLEDGMENTS}

This work was funded under the Austrian COMET Program by the Austrian Federal Ministry of Transport, Innovation and Technology (BMVIT); the Austrian Federal Ministry of Economy, Family and Youth (BMWFJ); and the State of Styria (Styrian Funding Agency SFG). The authors would like to thank the extrusion team of RCPE GmbH, Graz, Austria, for their assistance with the hot-melt extrusion process.

Conflict of interest The authors declare that they have no competing interests.

\section{REFERENCES}

1. Mastropietro DJ, Omidian H. Current approaches in tamperresistant and abuse-deterrent formulations. Drug Dev Ind Pharm. 2013;39(5):1-14.

2. Katz N. Abuse-deterrent opioid formulations: are they a pipe dream? Curr Rheumatol Rep. 2008;10(1):11-8. 
3. Gourlay GK. Sustained relief of chronic pain: pharmacokinetics of sustained release morphine. Clin Pharmacokinet. 1998;35(3):173-90.

4. Skelly JP, Amidon GL, Barr WH, Benet LZ, Carter JE, Robinson JR, et al. In vitro and in vivo testing and correlation for oral controlled/modified-release dosage forms. Pharm Res. 1990;7(9):975-82.

5. Walden M, Nicholls FA, Smith KJ, Tucker GT. The effect of ethanol on the release of opioids from oral prolonged-release preparations. Drug Dev Ind Pharm. 2007;33(10):1101-11.

6. Webster LR. Update on abuse-resistant and abuse-deterrent approaches to opioid formulations. Pain Med. 2009;10(S2):S124S33.

7. Webster LR, Bath B, Medve RA. Opioid formulations in development designed to curtail abuse: who is the target? Expert Opin Investig Drugs. 2009;18(3):255-63.

8. FDA guidance for industry abuse-deterrent opioids-evaluation and labeling 2015 [11 Jun 2015]. Available from: www.fda.gov/ downloads/Drugs/GuidanceComplianceRegulatoryInformation/ Guidances/UCM334743.pdf.

9. Herry C, Monti A, Vauzelle-Kervroedan F, Oury P, Michel L. Reducing abuse of orally administered prescription opioids using formulation technologies. J Drug Deliv Sci Tech. 2013;23(2):103-10.

10. FDA approves abuse-deterrent labeling for reformulated OxyContin [12 Feb 2015]. Available from: http://www.fda.gov/ NewsEvents/Newsroom/PressAnnouncements/ucm348252.htm.

11. FDA approves Targiniq ER with abuse-deterrent properties [12 Feb 2015]. Available from: http://www.fda.gov/Drugs/DrugSafety/ PostmarketDrugSafetyInformationforPatientsandProviders/ ucm406290.htm.

12. FDA approves labeling with abuse-deterrent features for third extended-release opioid analgesic [12 Feb 2015]. Available from: h t t p : / / w w w.fda.gov/News Even t s / N e w s r o o m/ PressAnnouncements/ucm419288.htm.

13. Purdue Pharma L.P. receives FDA approval for Hysingla ${ }^{\mathrm{TM}} \mathrm{ER}$ (hydrocodone bitartrate) extended-release tablets CII, a oncedaily opioid analgesic formulated with abuse-deterrent properties [04 Feb 2015]. Available from: http://www.purduepharma.com/ news-media/2014/11/purdue-pharma-1-p-receives-fda-approvalfor-hysinglatm-er-hydrocodone-bitartrate-extended-release-tablets-cii-a-once-daily-opioid-analgesic-formulated-with-abuse-deterrent-properties/.

14. Zogenix receives FDA approval for Zohydro ${ }^{\mathrm{TM}}$ ER (hydrocodone bitartrate) extended-release capsules [04 Feb 2015]. Available from: http://ir.zogenix.com/ phoenix.zhtml?c=220862\&p=irol-newsArticle \&ID=1868848.

15. Vosburg SK, Jones JD, Manubay JM, Ashworth JB, Benedek IH, Comer SD. Assessment of a formulation designed to be crushresistant in prescription opioid abusers. Drug Alcohol Depend. 2012;126(1-2):206-15.

16. Sokolowska M. FDA meeting on ADF-development and evaluation of abuse deterrent opioid formulations, part 12014 [12 Feb 2015]. Available from: http://www.fda.gov/downloads/Drugs/ NewsEvents/UCM422383.pdf.

17. Jedinger N, Khinast J, Roblegg E. The design of controlledrelease formulations resistant to alcohol-induced dose dumping-a review. Eur J Pharm Biopharm. 2014;87(2):217-26.

18. White JM, Irvine RJ. Mechanisms of fatal opioid overdose. Addiction. 1999;94(7):961-72.

19. Wening K, Barnscheid L, Schwier S, Geißler A, inventors; Grünenthal $\mathrm{GmbH}$, assignee. Tamper-resistant dosage form containing ethylenevinyl acetate polymer patent. US 2015/0017250 A1. 2015.

20. Bartholomaeus JH, Ashworth JB, Stahlberg H-J, Galia E, Strothmann K. Innovative formulation technology protecting intended drug action. Drug Dev Deliv. 2012;12(8):76-81.

21. Khinast J, Baumgartner R, Roblegg E. Nano-extrusion: a onestep process for manufacturing of solid nanoparticle formulations directly from the liquid phase. AAPS PharmSciTech. 2013;14(2):601-4.

22. Baumgartner R, Eitzlmayr A, Matsko N, Tetyczka C, Khinast J, Roblegg E. Nano-extrusion: a promising tool for continuous manufacturing of solid nano-formulations. Int J Pharm. 2014;477:1-11.

23. Treffer D, Wahl PR, Hörmann TR, Markl D, Schrank S, Jones I, et al. In-line implementation of an image-based particle size measurement tool to monitor hot-melt extruded pellets. Int $\mathrm{J}$ Pharm. 2014;466(1-2):181-9.

24. Bialleck S, Rein H. Preparation of starch-based pellets by hotmelt extrusion. Eur J Pharm Biopharm. 2011;79(2):440-8.

25. Rosiaux Y, Muschert S, Chokshi R, Leclercq B, Siepmann F, Siepmann J. Ethanol-resistant polymeric film coatings for controlled drug delivery. J Control Release. 2013;169(1-2):1-9.

26. Rosiaux Y, Velghe C, Muschert S, Chokshi R, Leclercq B, Siepmann F, et al. Ethanol-resistant ethylcellulose/guar gum coatings-importance of formulation parameters. Eur J Pharm Biopharm. 2013;85((3, Part B)):1250-8.

27. Rosiaux Y, Velghe C, Muschert S, Chokshi R, Leclercq B, Siepmann $\mathrm{F}$, et al. Mechanisms controlling theophylline release from ethanolresistant coated pellets. Pharm Res. 2014;31(3):731-41.

28. Shipway PH, Hutchings IM. Fracture of brittle spheres under compression and impact loading. I. Elastic stress distributions. Philos Mag A. 1993;67(6):1389-404.

29. Moore JW, Flanner HH. Mathematical comparison of dissolution profiles. Pharm Techno. 1996;20:64-74.

30. Paruta AN. Solubility profiles for antipyrine and aminopyrine in hydroalcoholic solutions. J Pharm Sci. 1967;56(12): 1565-9.

31. Jedinger N, Schrank S, Mohr S, Feichtinger A, Khinast J, Roblegg E. Alcohol dose dumping: the influence of ethanol on hot-melt extruded pellets comprising solid lipids. Eur J Pharm Biopharm. 2015;92:83-95.

32. Li A, Yalkowsky SH. Solubility of organic solutes in ethanol/ water mixtures. J Pharm Sci. 1994;83(12):1735-40.

33. Seedher N, Bhatia S. Solubility enhancement of cox-2 inhibitors using various solvent systems. AAPS PharmSciTech. 2003;4(3):36-44

34. Yu F, Prashantha K, Soulestin J, Lacrampe M-F, Krawczak P. Plasticized-starch/poly (ethylene oxide) blends prepared by extrusion. Carbohyd Polym. 2013;91(1):253-61.

35. Liu H, Xie F, Yu L, Chen L, Li L. Thermal processing of starchbased polymers. Prog Polym Sci. 2009;34(12):1348-68.

36. Zohuriaan MJ, Shokrolahi F. Thermal studies on natural and modified gums. Polym Test. 2004;23(5):575-9.

37. Kipping T, Trindade R, Rein H. The use of hot-melt extruded corn starch matrices as drug carrier systems: a thermophysical characterization. Starch - Stärke. 2014;66(9-10):923-33.

38. Liu P, Yu L, Liu H, Chen L, Li L. Glass transition temperature of starch studied by a high-speed DSC. Carbohyd Polym. 2009;77(2):250-3.

39. Bialleck S. Herstellung von Polysaccharidpellets mittels Schmelzextrusion Bonn: Rheinische Friedrich-WilhelmsUniversität 2011. Available from: http://hss.ulb.uni-bonn.de/ 2012/2743/2743.htm.

40. Liu H, Yu L, Xie F, Chen L. Gelatinization of cornstarch with different amylose/amylopectin content. Carbohyd Polym. 2006;65(3):357-63.

41. Mothé CG, Rao MA. Thermal behavior of gum arabic in comparison with cashew gum. Thermochim Acta. 2000;357-358:9-13.

42. Wauer GF, Rein H. Solid solutions of tramadol- $\mathrm{HCl}$ based on starch. Pharm Ind. 2010;72:1973-9.

43. Petruševski G, Ugarkovic S, Makreski P. Solid-state transformation of the pseudopolymorphic forms of codeine phosphate hemihydrate and codeine phosphate sesquihydrate monitored by vibrational spectroscopy and thermal analysis. J Mol Struct. 2011;993(1-3):328-35.

44. Toti US, Soppimath KS, Mallikarjuna NN, Aminabhavi TM. Acrylamide-grafted-acacia gum polymer matrix tablets as erosion-controlled drug delivery systems. J Appl Polym Sci. 2004;93(5):2245-53.

45. Talukdar MM, Kinget R. Swelling and drug release behaviour of xanthan gum matrix tablets. Int J Pharm. 1995;120(1):63-72.

46. Vendruscolo CW, Andreazza IF, Ganter JLMS, Ferrero C, Bresolin TMB. Xanthan and galactomannan (from M. scabrella) matrix tablets for oral controlled delivery of theophylline. Int J Pharm. 2005;296(1-2):1-11.

47. FMC. BioPolymer Aquacoat ${ }^{\circledR}$ ARC [27 May 2013]. Available from: http://www.fmcbiopolymer.com/Pharmaceutical/Products/ NEWAquacoatARC.aspx.

48. Bialleck S, Rein H. Drug release mechanisms of hot-melt extruded starch-based pellets. Starch - Stärke. 2012;64(5):408-19. 